\title{
Risk Incorporation into the Capital Budgeting process of Solar Power Plants
}

\author{
Abhishek Jha, Suneel Arora
}

\begin{abstract}
The following article deals with a new approach of incorporating risk profile of a solar power project into the Capital Budgeting process. As revealed in the literature review, the current capital budgeting practices being followed in the industry suffers from practice of non sophisticated methods of risk assessment. These include sensitivity and scenario analyses only.
\end{abstract}

Index Terms - Risk, Monte Carlo, Capital, Budgeting, Solar, Plant

\section{INTRODUCTION}

The present study deals with the risk related aspects of Investment or Capital Budgeting. Risk profile of a project is an important aspect of Capital Budgeting. Errors in estimating risk profile of a project could prove costly in the long term scenario of a project. If risk were erroneously determined to be lesser than it actually is then that would lead to unprofitable projects being selected. On the other hand, if risk is erroneously determined to be higher than it actually is then that would lead to profitable projects being rejected. Preliminary investigation and literature review has revealed that risk is not adequately incorporated into the capital budgeting process., Rossi (2015), Kester and Robbins (2011), Chan, Haddad and Sterk (2008), Lam, Wang \& Lam (2007), Arold \& Hatzopolous (2000) have discovered through their research that risk assessment methods being followed by most organizations are not sophisticated enough to adequately incorporate risk profile. Hence, a need was identified so as to adequately incorporate risk profile of the project into the capital budgeting process. Risk profiles of projects related with a diverse industry would differ very widely. It would not be very logical to find a solution such that risk profile of a diverse industry can be adequately incorporated into the capital budgeting process. Hence, a particular industry needs to be chosen such that its risk profile can be appropriately studied.

For the present study, solar power industry has been chosen. Solar power is an upcoming industry in India. The rising need for electric power requires huge investments in electric power industry. Thermal power industry is usually associated with environmental damages. Hence, Govt. of India is currently promoting renewable electric power industry such as solar power. The trend of installing solar power panels is catching up in metropolitan homes and businesses. There is a phenomenon of net metering where the extra power

Revised Manuscript Received on July 5, 2019.

Abhishek Jha, PhD Research Scholar, School of Management, G.D. Goenka University, Sohna, India,

Dr. Suneel Arora, PhD Guide, Professor, School of Management, G.D. Goenka University, Sohna, India generated from the solar panels can be transferred back to the mains. This way electricity bill is being reduced by individual and corporate customers.

\section{LITERATURE REVIEW}

Risk assessment is another significant factor to consider in Capital Budgeting process. An incorrect risk assessment may lead to incorrect discount or hurdle rate being utilized by the firm. An incorrect discount or hurdle rate may lead the firm to an accurate Capital Budgeting decision. Studies conducted in foreign countries like Arold and Hatzopolous (2000), Bennouna, Meredit and Marchant (2010), Chan, Haddad and Sterk (2008), Kester and Robbins (2011), Lam, Wang and Lam (2007), Rossi (2015) have claimed that risk assessment techniques being followed by most firms are not sophisticated. Hence, this reveals a research gap which needs to be investigated. Research needs to be done for ascertaining the exact reasons for not following sophisticated techniques of risk assessment. The proposed study should reveal the appropriate and accurate methods for risk assessment and the adequate way to incorporate risk in the Capital Budgeting process.

As for studies conducted on Indian or nearby countries they also did not reveal a completely different picture. It has been revealed that risk assessment is not carried out by following the modern and new sophisticated methods of Monte Carlo simulation, Fuzzy Logic or Decision Tree analysis. Most of the studies have revealed the fact that firms mainly relied on sensitivity and scenario analysis to conduct risk assessment. Anand (2002), Batra and Verma (2017), Jain and Yadav (2005), Kengatharan (2017), Nurullah and Kengatharan (2015) and Verma, Gupta and Batra (2009) have all identified that obsolete methods like sensitivity and scenario analysis are still fashionable with firms. Hence, a gap is identified and research is required to ascertain the exact reasons why sophisticated methods are not being carried out to assess risk.

Arold and Hatzopolous (2000) investigated Capital Budgeting practices of UK firms to assess and analyze the gaps between theory and practice. They followed a methodology of a structured survey method but it included encouragement for open ended answers. The advantage of such an approach is that the responses of open ended answers and insights can be assumed to offer more useful and appropriate responses. 96 usable responses were received which is a fairly normal population to analyze. 
The findings were compared and contrasted with earlier studies of similar nature which were a means to understand changes. Although the study supported the claim of there being a theory practice gap getting reduced but use of theoretically non supported methods are not decreasing. It was revealed by the author that there is a limited tendency towards a more sophisticated assessment of project risk.

Chan, Haddad and Sterk (2008) worked to elicit information on Capital Budgeting practices being undertaken by Chinese firms. The survey method did not work much on questionnaire and simply utilized modified versions of questionnaires/ instruments of survey used by studies of Graham and Harvey (2002) and Gitman and Forrester (1977). Hence, the information gathered will only be limited to some extent. Usable responses were received from 54 firms raising doubts of having received biased responses. The contacted persons were senior managers or in senior positions with sufficient experience in the firm and consequently most suited to provide required and relevant information. It was not investigated by the researcher why a considerable number of firms do not differentiate risks among projects and incorporate the difference in the capital budgeting process.

Updating of previous findings on Capital Budgeting practices being followed at listed Irish companies were attempted by Kester and Robbins (2011). The authors were innovative in sending Postal Questionnaires for the survey which hid the identity of the respondents thereby trying to get more response. Such an approach has merit that response rate has chances of becoming high but the inherent demerit is that further probes cannot be done. Response rate was a moderate $41.9 \%$ for the study. Old methods such as Sensitivity Analysis and Scenario Analysis were revealed to be the most preferred techniques for risk assessment. Sophisticated methods like probabilistic simulation were revealed to be least likely to be utilized. The exact reasons for not using project risk adjusted WACC values by a majority of the respondents could not be investigated. Furthermore, the reasons for not utilizing sophisticated risk assessment methods could also not be probed.

Lam, Wang \& Lam (2007) investigated and studied capital budgeting practices of building contractors in Hong Kong. It can be fairly assumed that Questionnaire was limited in nature as it was a modified version of the one already used by another author. Contractors were classified in several groups and analyzed by applying Anova test which is a comparatively better way to analyze as compared to descriptive studies. Risk was identified as being treated significant by the study but the corresponding adequate incorporation was not apparent as outdated methods of shortening payback and increasing discount rate were being used. The study identified the significance of use of computers and/or information technology in decision making but failed to investigate further why they have not been utilized. The study missed to investigate the reasons of not pursuing sophisticated methods of risk incorporation.
Bennouna, Meredit and Marchant (2010) made an attempt to update the research carried on Canadian firms to determine their Capital Budgeting techniques. The research did not tried to modify the sampling pattern much from the previous studies. The procedure subsequently helped in doing comparison among different things. A though and fairly elaborate literature review was included in the study. Valid responses were received from merely 88 firms with no non response bias test. This was a slight demerit. A considerable number of $36.6 \%$ of the respondent firms used the same discount rate for different projects which is not recommended academically. The use of risk analysis tools were revealed to be increasing over the years. The methods utilized for risk assessment and incorporation were the old methods of sensitivity analysis, scenario analysis and risk adjusted discount rate being the most important and most utilized ones. The comparison with past data comes with a flaw that underlying factors such as technology and formal training had undergone a drastic change over the years. The study failed to probe deeply the reasons for not pursuing sophisticated methods of risk assessment like Monte Carlo, Decision Tree and Fuzzy Logic methods.

Verbeeten (2006) conducted a research in which Dutch organizations were studied an attempt was made to analyze the relationship between uncertainty and the application of sophisticated Capital Budgeting methods. The sample size was appropriate and more than required for the successful completion of study. Factor Analysis was smartly used to determine various features of uncertainties. Control variables were identified and were held constant and correlation analysis was utilized to determine the relationship between various variables. Various types of uncertainties were correlated with Capital Budgeting techniques and the results were analyzed. The best aspect of the study was utilization of multiple regression to analyze the effect and impact of uncertainty on sophistication of Capital Budgeting methods. Uncertainty which is mainly financial in nature was found to be the single greatest factor in incorporation of sophisticated techniques. Size was revealed to be correlated with sophistication of Capital Budgeting methods. Nature of industry was found to have an effect on sophistication too with financial service industry being the frontrunner in application of sophisticated Capital Budgeting methods. The greatest limitation of the research is that previous researches have been used to identify various aspects of the study which curtails the independence of the study to some extent.

A detailed research of literature reviews was conducted by Haka (2006). The scope of the study spanned several centuries. The study ascertained historical development of capital budgeting and related aspects in great detail. Studies which were being carried out from the period of 1582 to 2001 were studied to understand the developments. The study reveals a carefully conducted thorough analysis of previous literature in the subject area. Detailed analysis has been carried out on why academically recommended methods took a very long time to become acceptable to the firms. The research tried to compare several publications on the

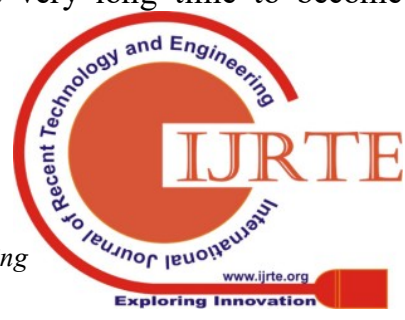


parameters of their response rate, survey year and sample details in order to compare their studies. The research also portrayed reviews of previous literature in a table form displaying the contents in the form of assumptions, issues and implications for capital budgeting.

The concise presentation was very informative and insightful. In a rare occurrence, the research conducted an in depth study on post audit studies of capital budgeting. Research emphasized the fact that most firms do not utilize capital budgeting audits very carefully and extensively. Even if they do pay attention to it, they do not abandon non performing projects prematurely before sufficient completion. The author acknowledged the importance of risk to be adequately incorporated into the capital budgeting process.

An in depth review of previous literature was conducted by Clancy and Collins (2014) on capital budgeting. The duration of the research for literature review is only decade long. The study may have missed to analyze improvements in capital budgeting over a sufficiently long period of time. The research prepared a table of literature review by journal and method of research, by topic and method of research and by journal and topic. It was emphasized that there is a necessity to research the diminishing of the perception of project risk with an increase in other perceptible benefits. It was also emphasized by the authors that there is a requirement to do more studies on strategic benefits of the project. Behavioural finance aspects needs to be further researched as additionally advised by the authors.

An exploratory study was conducted by Rossi (2015) employing both of qualitative and quantitative methods to analyze different features of Capital Budgeting practices being followed in southern Italy. AIDA was utilized to carefully select potential respondents. It is a detailed database of companies in Italy including most of their required information. Descriptive approach has been utilized to present information. It was also supplemented by a Chi Square test to ascertain and analyze the association among different variables. Qualitative aspects and issues were incorporated into the study to be able to explain various associations amongst variables. Response rate was a less than moderate $30 \%$ which may be considered quite significant for a huge total number of targeted respondents of 240. A higher sample size is associated with providing a normal distribution in which most of the parametric statistical tests may be appropriately used. In a surprising observation by the author, $70 \%$ of the respondents were revealed to pursue academically unsound non quantitative methods of risk assessment. The reasons for pursuing multiple non-academically recommended techniques in Capital Budgeting like seldom use of sound techniques such as NPV, perusal of poor risk profiling techniques and poor cost of capital estimation techniques have not been convincingly enquired. The greatest demerit of the research is that most firms included as sample had decision makers involved in capital budgeting who had no formal training. Hence, they was maximum likelihood of getting biased answers.

A survey was conducted by Anand (2002) on 81 CFOs in India to ascertain their corporate finance practices. The survey nature was kept broad based and involved ascertaining the various inter-relationships among different variables. The questionnaire was worked upon and final one was made very concise and investigative. This helped in getting a suitable response rate. Financial statistics of firms were gathered by secondary sources thereby shortening the questionnaire. Diversification of the sample according to the nature of industry added on more important dimension to the collected data. Variation of responses by characteristics of the firm was effectively checked by Mann-Whitney U test. The sophisticated techniques of risk assessment were ascertained to be unpopular amongst firms. 2002 was a period in which computers and Information Technology ruled the roost in Indian firms. Hence, lack of knowledge or availability of sophisticated techniques of risk assessment like Monte Carlo or Decision Tree cannot be given as a reason. The study did not probe deeply the reasons for non sophisticated methods to be carried out by firms and especially that by smaller ones.

A study was carried out by Verma, Gupta and Batra (2009) on Capital Budgeting practices of 100 diverse Indian manufacturing firms. The most positive feature of the study was the use of an elaborate questionnaire. Another positive feature was the maintenance of sufficient diversity for the sampled firms. CFOs were convinced, by taking great pains, to establish the confidentiality of the survey. Nevertheless, initial responses received were confirmed to be biased. The study did find that obsolete methods like sensitivity and scenario analysis were still popular with the firms. The reasons for doing so were not probed further.

A study was conducted by Jain and Yadav (2005) on Indian public sector undertakings and an attempt was made to ascertain details of Capital Budgeting preferences and related aspects of these firms. The study was conducted on a considerable number of 137 PSUs which can be fairly considered representative of the population. The authors ascertained that among the methods of risk incorporation, sensitivity analysis was the most popular technique. It was followed by shorter payback period and then by higher required rate of return for riskier projects. The corresponding percentages of firms which follow such techniques as revealed by the study were 59, 33 and 23 percent respectively. Sensitivity Analysis was to be the most preferred technique for manufacturing PSUs with three fourth of PSUs supporting it. Service PSUs were revealed to push for shorter payback period with about 46 percent PSUs favouring it. The modern and sophisticated methods of risk assessment like Monte Carlo, Decision Tree and Fuzzy Logic were not found to be popular with the firms. The research missed to further probe the reasons for not perusal of these sophisticated methods of risk assessment by the firms.

186 CFOs of Sri Lankan firms were surveyed by Kengatharan (2017) to ascertain and analyze the effect of moderation of uncertainty between Capital Budgeting techniques and their performance. A suitably large sample size was a positive feature of the research. A verified version which had already been utilized by previous researches was used for the study. Statistical tests utilized were highly rigorous so as to check significance and make accurate inferences. Increased 
social uncertainty was revealed to hamper the positive relationship between sophisticated Capital Budgeting techniques and performance.

It was indirectly pointed out through the study that risk assessment and incorporation is not adequately carried out in current firms. There is requirement of studies which may investigate this aspect of the risk assessment and incorporation process of Capital Budgeting.

Arthur, Gyamfi and Appiah (2013) analyzed probability distribution in Kumasi, Ghana and came out with a conclusion that the solar irradiations for the months of June to December could be equally well be fitted to the Weibull, Exponential, Gamma and Geometric distributions while that for April would be best fitted to only Weibull distributions.

Listed firms in Sri Lanka were analyzed by Nurullah and Kengatharan (2015). 32 listed firms of Colombo stock exchange were selected and their CFOs surveyed. The apparent drawback of the study is that only large firms were selected for the study. New aspects of research may have been ignored by the authors as an old questionnaire based on earlier papers was used for the study. An 80 percent response rate signifies an unusually high response rate which may indicate biased responses to some extent. A non parametric test like Chi square test was utilized to establish and analyze relationship amongst various variables. Outdated methods like Sensitivity and scenario analysis were revealed to be the most preferred techniques for risk assessment. The research missed to further probe the reasons of not utilizing sophisticated techniques of risk assessment like Monte Carlo or Decision Tree. These techniques are readily available in the market due to presence of advanced information technology in 21 st century and their non popularity should be probed further.

Batra \& Verma (2017) conducted a recent study on Indian firms listed in BSE to ascertain their latest Capital Budgeting methods. The final usable sample with all desired information consisted of 77 firms. The study may have ignored other aspects as the questionnaire was designed after going through only one research paper. The study identified that sensitivity analysis is still popular with firms. Hence, the firms have not started using sophisticated methods of risk assessment.

A study by Jape and Korde (2014) tried to investigate the gap between the theory and practice in corporate finance areas in Mumbai based firms. The paper is a literature review article which tries to find out the gaps in those studies. Literature has been adequately studied and the necessary gaps identified. Non sophistication of risk assessment and incorporation methods has been identified by the study. The paper has reviewed mostly old papers of 2002 or earlier despite being published in 2014. Failure to include latest research is a serious limitation of the study.

\section{RISK INCORPORATION MODEL}

Indian government allows anyone to set up a Solar Power Plant with a capacity range of $1 \mathrm{KW}$ to $1 \mathrm{MW}$ on any rooftop space. The Ministry of New and Renewable Energy has issued the latest guidelines which state that anyone can generate electricity through solar power plant. The surplus electricity generated may then be exported back to the grid through Net-metering system. The installation of net-metering at the concerned site would enable it to be connected to grid with the help of State Electricity Board/Distribution Companies. Ministry of New and Renewable Energy and State Nodal Agencies do also provide around $30 \%-70 \%$ subsidy benefits for residential, institutional as well as non-profit organizations.Out of two available models of investment which are CAPEX and OPEX, we would be discussing OPEX model. In CAPEX model, the investment made is one time. The unit belongs to the purchaser and the total responsibility lies totally with the purchaser. In OPEX model, the company involved in System Installation would install the complete system incurring their own cost for setting up a system on a rooftop through a 10 to 25 year Power Purchase Agreement. After the installation, one just needs to pay per unit charges on monthly basis. The PPA rates which vary from Rs. 3 to Rs. 7 are dependent on the size of the installation, time period of PPA and the credit rating of the concerned firm. OPEX model works best for any institution, business or industry where the installation size is more than $100 \mathrm{~kW}$. We would be considering On Grid Solar Power Plants. On Grid is grid or mains connected system. This type of system would run any home appliance or any other load without any limits. If the connected load exceeds the solar power plant capacity, it would draw power from the grid automatically. If connected load draws less power than the excess power generated by solar power plant is fed to the grid. This type of arrangement is effective in reducing electricity bills.

In Opex model, the customer purchasing the PPA doesn't have to worry about upfront construction and maintenance costs. A Power Purchase Agreement is a formally written agreement between the power generator and customer where terms and conditions of the purchase are clearly spelt out. The details include the duration of the power purchase agreement, the power tariff and annual increments if they are applicable. The discussed model of a power plant is as given below:-

Capacity of the power plant:- $1 \mathrm{MW}$

Degradation 1st 10 years:- $0.05 \%$

Degradation:- 11 th to 25 th years :- $0.67 \%$

Debt Percentage :- $70 \%$

Equity Percentage :- 30\%

Indian Rate of Interest :- 13\%

Repayment period of Indian Loan :- 11 years

Foreign Rate of Interest:- 10\%

Repayment period of Foreign Loan:- 15 years

Percent of Indian Loan considered:- 70\%

Cost of project per MW :- Rs. 450 Lakhs

Sale of Electricity :- Rs. 6.49/Unit 
O\&M Cost per MW :- Rs. 8 Lakhs /year

Depreciation :- $5.28 \%$

These figures have been obtained by a pilot survey of few solar power firms and directly provided by the website of Kenbrook Solar as detailed below:-

https://solarenergypanels.in/solar-power-plants/mw-solar-p ower-grid

A 1 MW Thermal power plant has considered for the study. Capital Cost has been estimated at Rs. 450 Lakhs for the power plant. Debt Equity Ratio as mandated by Tariff Regulations is 70:30. Hence, Equity investment required is Rs. 135 Lakhs while Debt required is Rs. 315 Lakhs.

Five categories of risk have been identified as presented below:-

$\begin{array}{ll}\text { 1. } & \text { Very Low Risk } \\ \text { 2. } & \text { Low Risk } \\ \text { 3. } & \text { Average Risk } \\ \text { 4. } & \text { High Risk } \\ \text { 5. } & \text { Very High Risk }\end{array}$

Types of probability distributions of various variable factors have been considered on advice from experts in the industry and literature review to present a new approach of visualizing risk. These probability distributions have also been supported by statements which flow from logical considerations. They have been utilized in the current study to analyze the associated risks and present an approach which allows one to visualize probability distribution of NPVs in a better way.

Revenue from a solar power plant would be dependent on sunshine factors. Sunshine factors can be best represented by way of a Weibull distribution as partially explained by Arthur, Gyamfi and Appiah (2013). As presented in his study, solar irradiance in maximum number of months can be represented by a Weibull distribution. Interest and O\&M expenses are best explained by a lognormal distribution as the interest rates or O\&M expenses cannot take negative values. Both of these interest rates and O\&M expenses are logically expected to skew towards the right i.e. have a long right tail. This would be so because both of them are expected to have a more likelihood of having a lower value due to the firm's effort of keeping them down. The probability of having both of interest rates and O\&M cannot be expected to be zero even at very high values due to sudden worse economic conditions. Both these factors support a representation in lognormal distribution.

A probable estimation has been made to present the ease and feasibility with which probable NPVs of solar power projects can be visualized by inputting a probability distribution of various factors and their statistical parameters. The assumed probability distributions for these types of risk are as detailed below:-

Table 1:- Probability Distribution Parameters for Very Low Risk scenario

\begin{tabular}{|l|l|l|}
\hline Item & $\begin{array}{l}\text { Probability } \\
\text { Distribution }\end{array}$ & Min. Variation Values \\
\hline Revenue & Weibull & Location -112.6, Scale -1 , Shape -3 \\
\hline $\begin{array}{l}\text { Interest on } \\
\text { Loan }\end{array}$ & Lognormal & $\begin{array}{l}\text { Location }-0 \%, \text { Mean-12.1\%, } \\
\text { Std. Dev.-2\% of Mean Value }\end{array}$ \\
\hline $\begin{array}{l}\text { O\&Menses/Year } \\
\text { Expen }\end{array}$ & Lognormal & $\begin{array}{l}\text { Location }-0, \text { Mean }- \text { Rs. 8 Lakhs, } \\
\text { Std. Dev. }-2 \% \text { of Mean Value }\end{array}$ \\
\hline
\end{tabular}

Table 2:- Probability Distribution Parameters for Low Risk scenario

\begin{tabular}{|l|l|l|}
\hline Item & $\begin{array}{l}\text { Probability } \\
\text { Distribution }\end{array}$ & Min. Variation Values \\
\hline Revenue & Weibull & Location -112.6, Scale -1 , Shape -3 \\
\hline $\begin{array}{l}\text { Interest on } \\
\text { Loan }\end{array}$ & Lognormal & $\begin{array}{l}\text { Location }-0 \%, \text { Mean-12.1\%, } \\
\text { Std. Dev.-4\% of Mean Value }\end{array}$ \\
\hline $\begin{array}{l}\text { O\&M } \\
\text { Expenses/Year }\end{array}$ & Lognormal & $\begin{array}{l}\text { Location }-0, \text { Mean }- \text { Rs. 8 Lakhs, } \\
\text { Std. Dev. }-4 \% \text { of Mean Value }\end{array}$ \\
\hline
\end{tabular}

Table 3:- Probability Distribution Parameters for Average Risk scenario

\begin{tabular}{|l|l|l|}
\hline Item & $\begin{array}{l}\text { Probability } \\
\text { Distribution }\end{array}$ & Min. Variation Values \\
\hline Revenue & Weibull & Location -112.6, Scale -1 , Shape -3 \\
\hline $\begin{array}{l}\text { Interest on } \\
\text { Loan }\end{array}$ & Lognormal & $\begin{array}{l}\text { Location }-0 \% \text {, Mean-12.1\%, } \\
\text { Std. Dev.-6\% of Mean Value }\end{array}$ \\
\hline $\begin{array}{l}\text { O\&M } \\
\text { Expenses/Year }\end{array}$ & Lognormal & $\begin{array}{l}\text { Location }-0, \text { Mean }- \text { Rs. 8 Lakhs, } \\
\text { Std. Dev. }-6 \% \text { of Mean Value }\end{array}$ \\
\hline
\end{tabular}

Table 4:- Probability Distribution Parameters for High Risk scenario

\begin{tabular}{|l|l|l|}
\hline Item & $\begin{array}{l}\text { Probability } \\
\text { Distribution }\end{array}$ & Min. Variation Values \\
\hline Revenue & Weibull & Location -112.6, Scale -1 , Shape -3 \\
\hline $\begin{array}{l}\text { Interest on } \\
\text { Loan }\end{array}$ & Lognormal & $\begin{array}{l}\text { Location }-0 \% \text {, Mean-12.1\%, } \\
\text { Std. Dev.-8\% of Mean Value }\end{array}$ \\
\hline $\begin{array}{l}\text { O\&M } \\
\text { Expenses/Year }\end{array}$ & Lognormal & $\begin{array}{l}\text { Location }-0, \text { Mean }- \text { Rs. 8 Lakhs, } \\
\text { Std. Dev. }-8 \% \text { of Mean Value }\end{array}$ \\
\hline
\end{tabular}

Table 5:- Probability Distribution Parameters for Very High Risk scenario

\begin{tabular}{|l|l|l|}
\hline Item & $\begin{array}{l}\text { Probability } \\
\text { Distribution }\end{array}$ & Min. Variation Values \\
\hline Revenue & Weibull & Location -112.6, Scale -1, Shape -3 \\
\hline $\begin{array}{l}\text { Interest on } \\
\text { Loan }\end{array}$ & Lognormal & $\begin{array}{l}\text { Location }-0 \% \text {, Mean-12.1\%, } \\
\text { Std. Dev.-10\% of Mean Value }\end{array}$ \\
\hline $\begin{array}{l}\text { O\&M } \\
\text { Expenses/Year }\end{array}$ & Lognormal & $\begin{array}{l}\text { Location }-0, \text { Mean }- \text { Rs. 8 Lakhs, } \\
\text { Std. Dev. }-10 \% \text { of Mean Value }\end{array}$ \\
\hline
\end{tabular}

A time frame of 10 years has been envisaged for the solar power plant. It has been assumed that the solar power plant would be sold off at the purchase price minus the depreciated value after 10 years. A 10 year forecast has been prepared assuming the degradation to be negligible as it is not a significant number so as to distort the risk predictions. The Profit before Tax has been calculated for 10 future years along with their Present Value. It has been assumed that the residual value of the 
power plant would be sold after 10 years and the concerned PV would include this value. The calculations are as presented under:-

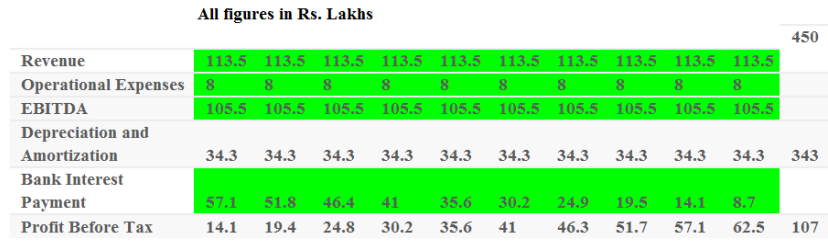

\section{$\$ 206.84$}

Figure 1:- Calculations of Profit before Tax and their PV (\$ sign can be ignored)

Crystal Ball software have been used to predict variations of PV of Profit before Tax taking into account all parametric variations. The predictions are as depicted below for the very low and very high risk categories.

As evident in the outcome from Crystal Ball, the Standard deviation of PV of PBT was Rs. 1.77 Lakhs for the very low risk category and Rs. 8.27 Lakhs for very high risk category.

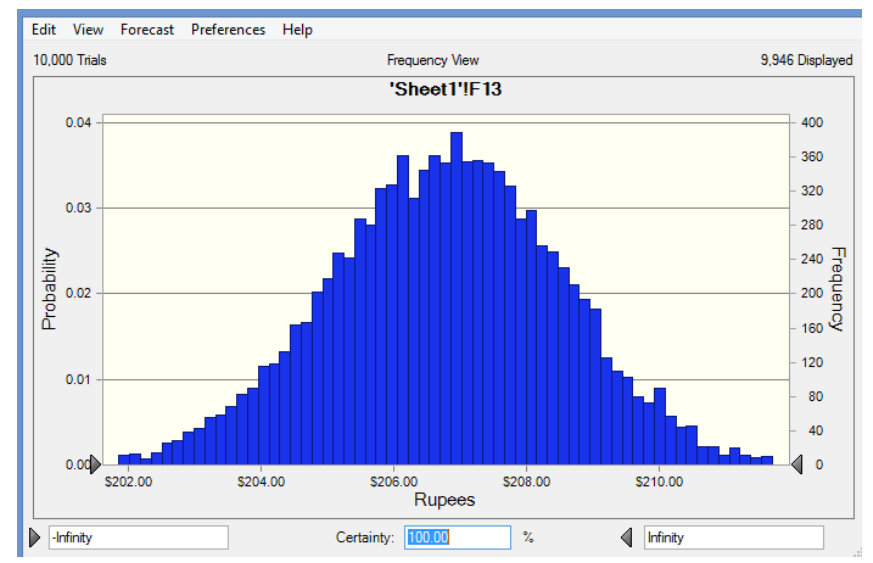

Figure 2:- Variations of PV of PBT for very low risk category ( $\$$ sign can be ignored. All figures in Rs. Lakhs)

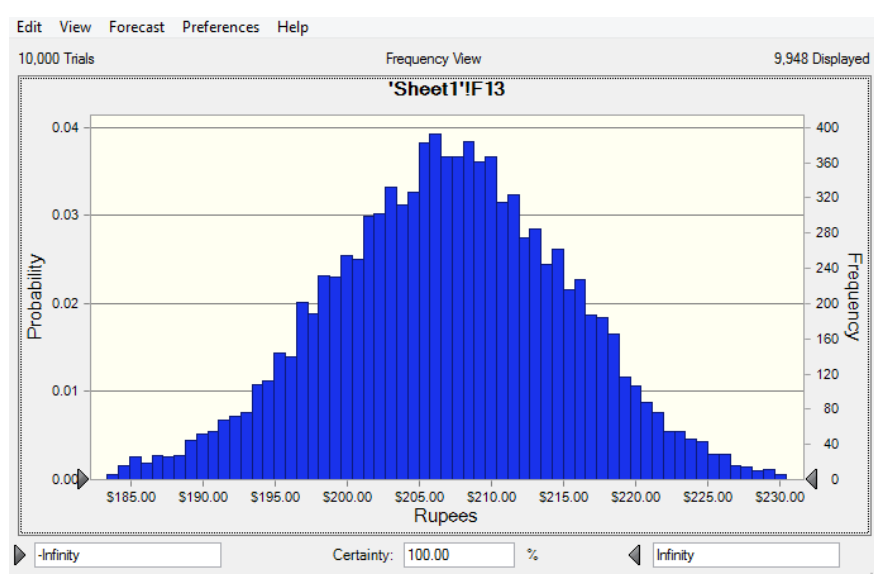

Figure 3:- Variations of PV of PBT for very high risk category ( $\$$ sign can be ignored. All figures in Rs. Lakhs)

Such standard deviation values of PV of PBT and their graphical spread can be used to change WACC or discounting values to incorporate the inherent risk present in such projects.

\section{RECOMMENDATIONS}

The recommendations of the study are as listed under:-

1. It is always a better idea to incorporate risk profile of a solar power project into the capital budgeting process.

2. Monte Carlo Simulation is a good way to analyze risks associated with the project. It is an improvement over sensitivity analysis and scenario analysis

3. One should always properly work out the variation in parameters involved in a solar power project in order to work out the variation in final NPV of the project.

4. The more number of trials one utilize in Monte Carlo the more refined the process becomes. However, the utility of using large number of trials decreases with an increasing number.

5. It is important to note that the presented values represent a way to actually visualize the final values. Due diligence should be practiced in order to work out the specific true probability distributions so that the variation of NPVs can be accurately visualized.

\section{CONCLUSION}

Risk profile of a solar power project has been revealed as not generally adequately incorporated into the capital budgeting process. Without an adequate incorporation of risk profile of a solar power plant, capital budgeting process remains considerably shallow. It has been observed that Monte Carlo simulations have proved to provide many elaborated insights into the risk factors involved in the solar power projects. These methods should be further researched and an effort made to capture real time information to be fed to these analysis methods. That will further improve these methods while allowing us to get useful insights about the risk factors. In a nutshell, the current study focuses more on new approaches rather than getting precise outcomes.

\section{REFERENCES}

1. D. Clancy, and D. Collins, "Capital budgeting research and practice: The state of the art", Advances in Management Accounting, vol. 24, pp. 117-161, September 2014.

2. F. Verbeeten, "Do organizations adopt sophisticated capital budgeting practices to deal with uncertainty in the investment decision?: A research note", Management Accounting Research vol. 17, no. 1, pp. 106-120, March 2006.

3. G.C. Arnold, P.D. Hatzopoulos, "The theory practice gap in capital budgeting: evidence from the United Kingdom", Journal of business finance \& Accounting, vol. 27, no. 5\&6, pp. 603-26, June 2000.

4. G. Kester and G. Robbins, "The capital budgeting practices of listed Irish companies: insights from CFOs on their investment appraisal techniques", Accountancy Ireland, vol. 43, no. 1, pp.28-30, February. 2011.

5. H. Chan, K. Haddad, and W. Sterk, "Capital budgeting practices of Chinese firms", Journal of Global Business Management, vol. 4, no. 2, 2008 .

6. K. Bennouna, G.G. Meredith, T. Marchant, "Improved capital budgeting decision making: evidence from Canada", Management decision, vol. 48, no. 2, pp. 225-247, March, 2010.

7. K.C. Lam, D. Wang, and M. C. K. Lam, "The capital budgeting evaluation practices (2004) of building contractors in Hong Kong", International Journal of Project Management, vol. 25, pp. 824-834, 2007.

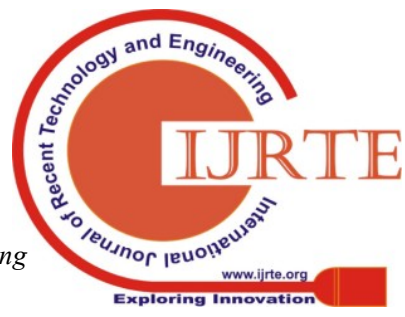


8. L. Kengatharan, "Moderating Effect of Social Uncertainty between Capital Budgeting Practices and Performance", International Journal of Accounting and Financial Reporting, vol. 7, pp. 79-95, 2017.

9. M. Anand, “Corporate finance practices in India: a survey.", Vikalpa, vol. 27, pp. 29-56, 2002.

10. M. Nurullah and L. Kengatharan, "Capital budgeting practices: evidence from Sri Lanka”, Journal of Advances in Management Research, vol. 12 , pp. 55-82, May 2015.

11. M. Rossi, "The use of capital budgeting techniques: an outlook from Italy", International Journal of Management Practice, vol. 8, no. 1, pp. 43-56, 2015.

12. P.K. Jain, and S. Yadav, "Financial management practices in public sector enterprises: a study of capital budgeting decisions", Journal of advances in management research, vol. 2, pp. 32-46, Jan 2005.

13. R. Batra, and S. Verma, "Capital budgeting practices in Indian companies”, IIMB Management Review, vol. 29, no. 1, pp. 29-44, March 2017.

14. S. Haka, "A review of the literature on capital budgeting and investment appraisal: past, present, and future musings", Handbooks of Management Accounting Research, vol. 2, pp. 697-728, 2006.

15. S.S. Jape, T. Korde, "Study of established financial management tools and techniques and their application by business houses (with reference to Mumbai based Companies period-2002-2012)" , Aweshkar Research Journal, vol. 18, no. 2, pp. 71-89, September 2014.

16. S. Verma, S. Gupta and R. Batra, "A Survey of Capital Budgeting Practices in Corporate India. Vision", The Journal of Business Perspective, vol. 13, no. 3, pp. 1-17, July 2009.

17. Y.D. Arthur, K.B. Gyamfi, S.K. Appiah, "Probability distributional analysis of hourly solar irradiation in Kumasi-Ghana", Internationa Journal of Business and Social Research, vol. 3, no. 3, pp. 63-75, 2013.

18. Kenbrooksolar.com, ' $1 \mathrm{~kW}-1 \mathrm{~mW}$ Solar Power Plant Detail, Return On Invesment \& Price Details 2019', 2019. [Online]. Available:https://solarenergypanels.in/solar-power-plants/mw-solar-pow er-grid. [Accessed: 25-Feb-2019]

\section{AUTHORS PROFILE}

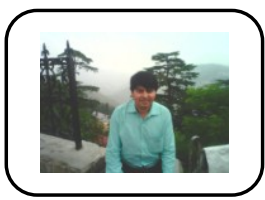

Abhishek Jha Abhishek Jha is a resourceful professional with more than 10 years of experience in Academics and Business \& Financial Research. He is currently pursuing PhD from GD Goenka University. He has served with reputed educational institutions like PDM College of Engineering, and BML Munjal University in the past. He has worked in Research Firms such as Accelerator Group LLC and Evalueserve.com Pvt. Ltd. He completed his MBA (International Business \& Finance) from Amity Business School, Noida and BE (Electronics) from DY Patil College of Engineering, Pune University. He has cleared UGC NET two times in June 2012 and in June 2013.

He has significant experience in having delivered superior training programmes on Finance, International Business, General Management and Economics. He is proficient in carrying out major responsibilities pertaining to Mergers \& Acquisition, Due Diligence and Business Modeling. . He has 10 publications in international and national journals, conferences proceedings and books chapters.

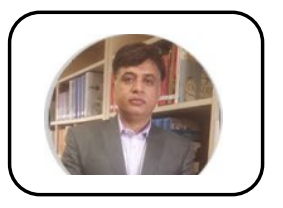

Dr. Suneel Arora Dr. Arora started his caree with Karvy Consultancy, Hyderabad but after a short period he received a $\mathrm{PhD}$ fellowship from Nirma University of Science and Technology, Ahmedabad and undertook a full-time $\mathrm{PhD}$ programme. During his $\mathrm{PhD}$, he was a visiting faculty at various institutes in Gujarat such as Institute of Technology, Nirma University; DD IT University; ICFAI Busines School; ICFAI Distance Learning Centre, Ahmedabad Chapter; S. K. Patel Institute of Management \& Computer Science, Gandhinagar. After defending his $\mathrm{PhD}$ thesis, he started his full time teaching career with ICFAI Business School.

He has worked on two government research projects and conducted MDPs. Before joining GDGU, he worked with Lancaster University for 9 years. He handled various responsibilities such as Director of PDGBM Program, Academic Conduct Officer and part of core committees. His research interest includes Corporate Reporting Practices, Environmental Disclosures, Corporate Finance and IFRS. He has $15+$ publications in international and national journals, conferences proceedings and books chapters. He also worked on two government research projects. 